\title{
BMJ Open Physical activity patterns in a representative sample of adolescents from the largest city in Latin America: a cross-sectional study in Sao Paulo
}

\author{
Gerson Ferrari (D) , ${ }^{1}$ Leandro F.M. Rezende, ${ }^{2}$ Gabriela Arantes Wagner, ${ }^{2}$ \\ Alex A Florindo, ${ }^{3,4}$ Maria Fernanda Tourinho Peres ${ }^{5}$
}

To cite: Ferrari G,

Rezende LF.M, Wagner GA, et al. Physical activity patterns in a representative sample of adolescents from the largest city in Latin America: a cross-sectional study in Sao Paulo. BMJ Open 2020;10:e037290. doi:10.1136/ bmjopen-2020-037290

- Prepublication history for this paper is available online. To view these files, please visit the journal online (http://dx.doi org/10.1136/bmjopen-2020037290).

Received 28 January 2020 Revised 18 June 2020 Accepted 13 July 2020
Check for updates

(C) Author(s) (or their employer(s)) 2020. Re-use permitted under CC BY-NC. No commercial re-use. See rights and permissions. Published by BMJ.

For numbered affiliations see end of article.

Correspondence to

Dr Gerson Ferrari;

gersonferrari08@yahoo.com.br

\section{ABSTRACT}

Objectives We examined the patterns of total

and domain-specific physical activity (PA) by sex, socioeconomic status and maternal education level in adolescents from Sao Paulo city, Brazil.

Design Cross-sectional study.

Participants We included a representative sample of 2682 (52.2\% boys) adolescents aged $14-15$ years from public and private schools in Sao Paulo, 2017. Socioeconomic status was assessed using a wealth index derived from principal component analysis. Descriptive analyses evaluated differences in total and domainspecific PA by sex, socioeconomic status and maternal education level.

Outcome measures We collected data on the frequency and duration that adolescents spent in each PA domain (active transportation, leisure PA and physical education classes) through a self-report questionnaire.

Results On average, adolescents spent $197.7 \mathrm{~min} /$ week (95\% Cl 190.6-204.8) in total PA. The proportion of adolescents achieving at least $60 \mathrm{~min} /$ day $(\geq 420 \mathrm{~min} /$ week) was $12.7 \%(95 \% \mathrm{Cl} 11.4-14.1)$, with a higher prevalence in boys $(18.3 \%)$ and in those with higher socioeconomic status (17.4\%). Similar patterns were observed for leisure PA and physical education classes. Active transportation was higher in girls $(46.0 \mathrm{~min} /$ week; $95 \% \mathrm{Cl} 42.6-49.6)$ than in boys $(43.4 \mathrm{~min} /$ week, $95 \% \mathrm{Cl} 39.9-46.6)$. Boys and adolescents with higher socioeconomic status and higher maternal education level had higher levels of total PA.

Conclusions We found a variation in patterns of total and domain-specific PA by sex, socioeconomic status and maternal education level in adolescents from Sao Paulo. Initiatives for promoting PA in adolescents should take these findings into account.

\section{INTRODUCTION}

The health benefits of physical activity (PA) during childhood and adolescence are well known. PA decreases the risk of cardiovascular disease and adiposity and improves cognitive development and cardiorespiratory and muscular fitness. ${ }^{1}$ In addition, PA during adolescence has been linked to a lower risk

\section{Strengths and limitations of this study}

- Use of a large sample of adolescents living in a megacity, Sao Paulo; therefore, the representativeness is high.

- Use of total and domain-specific physical activity (PA) data to describe adolescent's PA patterns by sex, socioeconomic status and maternal education level.

- PA was collected through a self-report questionnaire; therefore, measurement error is likely to have occurred.

- Out-of-school adolescents were not included in our study.

- Approximately 1 out of 10 adolescents did not report maternal education level.

of non-communicable diseases during adulthood. ${ }^{2}$ To achieve these health benefits, the WHO recommends that adolescents accumulate at least $60 \mathrm{~min} /$ day of moderate-tovigorous intensity PA (MVPA). ${ }^{3}$ In Brazil, only $29 \%$ of adolescents meet these PA guidelines, a scenario that is slightly better than the world average (19\%). ${ }^{4}$ The reasons for this low PA level in adolescents are not yet fully understood. ${ }^{5}$

In relation to a large number of correlates and determinants of PA, evidence has shown that some population strata have greater opportunities to achieve the recommended PA guidelines. ${ }^{6}$ A systematic review showed that young people with socioeconomic vulnerability have lower levels of $\mathrm{PA}^{7}$ In Brazil, the National School-Based Health Survey (Pesquisa Nacional de Saúde do Escolar - PeNSE) showed that boys and children of mothers with more years of schooling are more active in their leisure time than girls and adolescents of mothers with incomplete elementary school. ${ }^{8}$ 
An emerging area of research is the context in which PA occurs, also known as domains or modes of PA. ${ }^{1} \mathrm{PA}$ includes a diversity of organised (eg, sports activities and physical education classes) and unorganised activities (eg, active play or unorganised sport), as well as active transportation (eg, cycling to school). ${ }^{1}$ Assessing the patterns of total and domain-specific PA may provide a more complete understanding of this complex behaviour. For instance, perceived traffic and access to recreational and leisure facilities have been positively associated with engagement in sports. In contrast, the presence of adequate walking and cycling infrastructure, street connectivity and proximity to public spaces have been associated with increased active transportation. ${ }^{9}$ These findings suggest that PA determinants may differ according to PA domains. ${ }^{10} 11$

Promoting PA in adolescents living in megacities is an even greater challenge. Sao Paulo is among the 10 most urbanised and populous cities in the world, ${ }^{12}$ characterised by diverse cultural and socioeconomic backgrounds, as well as wide variation in disease distribution and lifestyles. In the last years, Sao Paulo has undergone an accelerated urbanisation process, along with a demographic, epidemiological and socioeconomic transition. ${ }^{13}$ Meanwhile, highly disorganised and heavy traffic, air and noise pollution, rising crime rates and high-income inequality persist in this megacity. ${ }^{13}$ These changes have produced changes in PA patterns in all age groups. ${ }^{14}{ }^{15}$ Systematic reviews indicated that most studies have been conducted in high-income countries. ${ }^{16}{ }^{17}$ In Brazil, previous studies have suggested that socioeconomic inequalities in access to leisure PA have decreased between 2009 and 2015, although it remains high. ${ }^{18}$ In addition, few studies have shown the pattern of total and domain-specific PA in adolescents living in megacities in low-income to middleincome countries. ${ }^{19}$

In the urban context of Sao Paulo, characterised by social fragmentation and inequalities in opportunities to engage in PA, the New Master Plan has emerged as an effective initiative to promote active life. ${ }^{20}$ This initiative improved an extensive network of bike paths created in Sao Paulo in 2014. In the last 5 years, the number of bike lanes has increased particularly in this city. This can be partly explained by the fact that bike lanes allow the temporary and regular use of public open spaces in urban contexts where there is relatively low availability of public recreation facilities and public spaces. Furthermore, bike lanes represent an opportunity to encourage the equitable and sustainable use of public spaces, as they have the potential to change transportation behaviours. ${ }^{21}$ Therefore, understanding the patterns of total and domain-specific PA by sex, socioeconomic status and maternal education can provide new insights and enable future research on how policies and interventions impact PA in adolescents. To describe the PA pattern in adolescents in Sao Paulo, we used data from a large representative sample of students, the Sao Paulo Project for the Social Development of Children and Adolescents (São Paulo para o desenvolvimento social de crianças e adolescentes - SP-PROSO).

\section{METHODS}

\section{Study design, sample and data collection}

SP-PROSO is a cross-sectional study including a representative sample of ninth-grade students from public and private schools in Sao Paulo, 2017. ${ }^{22}$ The schools' principal, responsible guardian and the adolescents themselves signed a consent form to participate in the study.

The target population included ninth-grade adolescents formally enrolled in schools in the city of Sao Paulo. According to the 2015 School Census, a total of 175854 students were enrolled in the ninth grade of 2086 private and public schools in Sao Paulo. The minimum sample size was determined to obtain estimates of population groups of at least $15 \%$ of the population $\left(n=n_{o} / 0.15\right)$, with an accuracy of (d) 0.06 and a sampling design effect of 1.7. The estimated minimum sample size was 2849 students. Considering a possible loss of $10 \%$, this number was increased to 3300 . The sampling strategy considered stratification by school type (state public, municipal public and private) and clustering by considering each class as a drawing unit. In total, 156 classes were randomly selected and 119 schools agreed to participate in the study. Of the 61 private schools drawn, 26 refused to participate and 3 did not respond to our invitation and were excluded. Of the public schools, there was only one loss among the state schools and seven among the municipal schools. Regarding the students, considering the number that attended classes on the day of data collection $(n=2816)$, 96 were not authorised by their parents or refused to participate in the study and 18 could not participate due to health-related and/or reading/comprehension issues. The final sample size was 2702 participants, which represented $94.8 \%$ of the calculated minimum sample size.

Adolescents filled out a self-report structured questionnaire available in their classrooms during regular school hours. The questionnaire was based on two validated questionnaires from the Global School-Based Student Health Survey ${ }^{23}$ and the Youth Risk Behaviour Surveillance System. ${ }^{24}$

\section{PA assessment}

The PA questionnaire asked participants about their weekly frequency and duration of active transportation (walking or cycling) to and from school, leisure PA and participation in physical education classes during the past week. This questionnaire has been used by the National Survey of School Health.$^{25}$ Measures of PA have been validated previously and showed satisfactory relative validity (sensitivity: $77.9 \%$; specificity: $69.1 \%$; accuracy index: $73.1 \%) .^{26}$

We calculated total PA by summing the minutes per week (min/week) of each PA domain. Adolescents were categorised as 'meeting' $(\geq 420 \mathrm{~min} /$ week) or 'not meeting' $(<420 \mathrm{~min} /$ week $)$ PA guidelines according to WHO's recommendations for adolescents. ${ }^{3} \mathrm{PA}$ in each domain was expressed as continuous (min/week) and categorical (participation in at least 2 days a week). Finally, we estimated the distribution of total PA according to PA 
domains (ie, to estimate the share of each PA domain in total PA).

\section{Sociodemographic variables}

The socioeconomic status was determined based on maternal education level and a series of questions that explored the possession of goods and the presence of a maid in the home. These questions were derived from the PeNSE. The PeNSE questionnaire included questions about the presence of goods in the home (the home where the adolescents actually lived). This questionnaire and method of measuring socioeconomic status have been widely used in Brazilian school surveys. ${ }^{27}$

As previously suggested by Barros and Victoria, the socioeconomic status was calculated through principal component analysis (PCA) ${ }^{27}$ PCA was ran adding to the model: maternal educational level (incomplete middle school, complete middle school, complete high school and complete higher education); school type (public or private); landline (yes or no), mobile phone (yes or no), internet computer in the room (yes or no), car (yes or no) and number of bathrooms inside the house. The first component of the PCA and estimated coefficients were obtained using the following equation: coefficient=loading $/ \mathrm{SD} \times 100$. The individual value was calculated from $\sum c_{i} v_{i}$, where $c_{i}$ is the coefficient and $v_{i}$ is the score for the ith variable. Socioeconomic status was categorised as tercile of the total wealth scores, being the first tercile the poorest group and the third tercile the wealthiest group. Total and domain-specific PA were also presented separately by sex and maternal education level.

\section{Patient and public involvement}

This cross-sectional study with adolescents did not involve patients in the design, recruitment, implementation or planning.

\section{Statistical analysis}

Total and domain-specific PA were described using absolute frequencies, mean (and its 95\% confidence intervals - CI) and median (and its interquartile range - IQR). Analyses were carried out according to sex, socioeconomic status and maternal education level. Mann-Whitney and Kruskal-Wallis tests were used to compare means and variances, and the $\mathrm{X}^{2}$ test was used to compare categorical variables. All analyses were performed using IBM SPSS (V.22, IBM Corp). ${ }^{28}$

\section{RESULTS}

On average, adolescents spent $197.7 \mathrm{~min}$ (95\% CI 190.6-204.8) in total PA per week, with a median value of $140 \mathrm{~min} /$ week (IQR: 55.0-280.0) (figure 1). Boys, adolescents with higher socioeconomic status and higher maternal education level presented higher levels of total PA. Mean differences in total PA were: $82 \mathrm{~min} /$ week higher in boys than girls; $57 \mathrm{~min} /$ week higher in those of high socioeconomic status compared with those of low

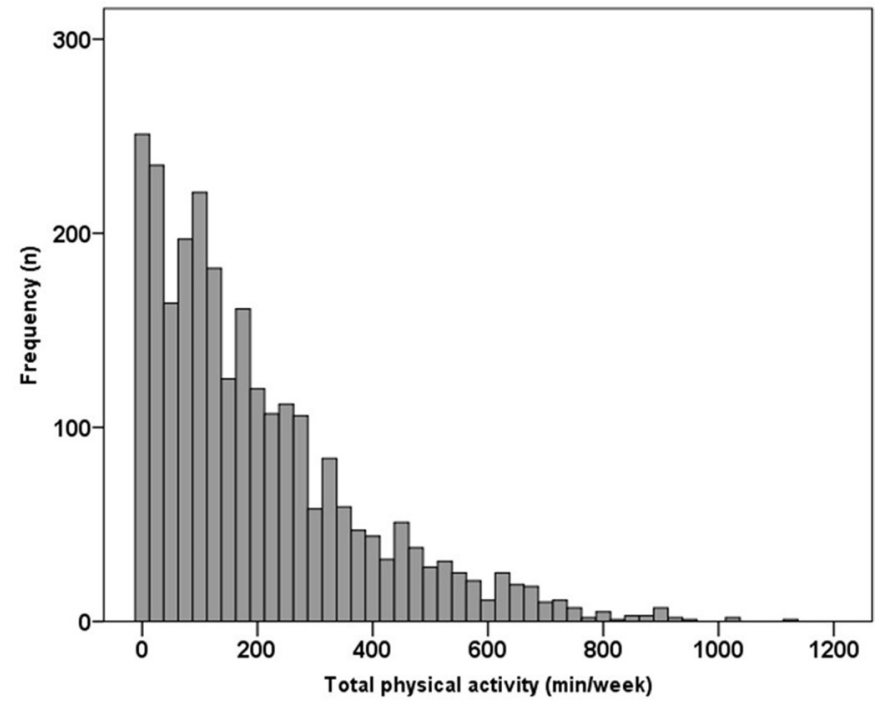

Figure 1 Distribution of total physical activity (min/week) in adolescents from Sao Paulo city. SP-PROSO, 2017.

socioeconomic status; $21 \mathrm{~min} /$ week higher in those whose mothers had complete higher education compared with those whose mothers did not complete middle school. The proportion of adolescents achieving $\geq 420 \mathrm{~min} /$ week of total PA was $12.7 \%$ (95\% CI 11.4-14.1), with a higher proportion in boys $(18.3 \%)$ than in girls $(6.8 \%)$, in the high socioeconomic group $(17.4 \%)$ than in the low socioeconomic group $(9.0 \%)$, and in those whose mothers completed higher education $(16.0 \%)$ than in those whose mothers did not complete middle school $(14.5 \%)$ (table 1).

Figure 2 shows the proportion of adolescents participating in at least 2 days/week in each of the three PA domains investigated: $65.2 \%$ for active transportation, $63.7 \%$ for leisure PA and $81.2 \%$ for participation in physical education classes.

Figure 3 displays the proportion of each domain-specific PA to total PA by sex, socioeconomic status, maternal education level and PA guidelines. The relative contribution of leisure PA was higher among adolescents with higher levels of PA. For instance, leisure PA contributed to $46.1 \%$ of total PA in boys, $49.5 \%$ in adolescents with high socioeconomic status, $46.2 \%$ in adolescents whose mothers completed high school and $55.7 \%$ in adolescents achieving PA guidelines.

In absolute terms, leisure PA contributed more to total PA in boys $(112.7 \mathrm{~min} /$ week $)$, in adolescents with high socioeconomic status (116.1 min/week) and in those whose mothers completed high school (106.0 min/week). In contrast, active transportation contributed more to total PA in girls $(46.0 \mathrm{~min} /$ week). Physical education classes had a higher share of total PA in boys (92.3 $\mathrm{min} /$ week), in adolescents with high socioeconomic status $(76.8 \mathrm{~min} /$ week) and in those whose mothers did not complete high school $(83.7 \mathrm{~min} /$ week $)$ (figure 4). 
Table 1 Sociodemographic characteristics associated with total physical activity in adolescents from Sao Paulo city. SPPROSO, 2017.

\begin{tabular}{|c|c|c|c|c|c|c|}
\hline Variables & $\mathbf{N}$ & $\%$ & Mean $(95 \% \mathrm{Cl})$ & Median (25-75) & $\geq 420 \mathrm{~min} /$ week $(95 \% \mathrm{Cl})$ & $P$ value† \\
\hline Total & 2682 & & 197.7 (190.6-204.8) & $140.0(55.0-280.0)$ & $12.7(11.4-14.1)$ & \\
\hline Sex & 261 & & & & & $<0.001$ \\
\hline Girls & 1247 & 47.8 & $155.8(146.2-164.9)$ & $105.0(30.0-225.0)$ & $6.8(5.2-8.1)$ & \\
\hline Socioeconomic status & 2682 & & & & & \\
\hline Middle & 890 & 33.2 & $197.8(185.2-210.8)$ & $140.0(70.0-275.0)$ & $12.5(10.3-14.7)$ & \\
\hline High & 899 & 33.5 & $230.1(217.2-243.9)$ & $190.0(85.0-330.0)$ & $17.4(15.0-19.9)$ & \\
\hline Maternal education level & 1855 & & & & & \\
\hline Did not complete middle school & 462 & 24.9 & 206.5 (187.4-226.7) & $140.0(50.0-303.7)$ & $14.5(11.4-17.9)$ & 0.093 \\
\hline Complete middle school & 366 & 19.7 & $186.6(167.8-206.0)$ & $130.0(60.0-240.0)$ & $9.8(6.7-13.0)$ & \\
\hline
\end{tabular}

\section{DISCUSSION}

The aim of this study was to describe the patterns of total and domain-specific PA by sex, socioeconomic status and maternal education level in adolescents from the largest city of Latin America, Sao Paulo. On average, adolescents spent $197.7 \mathrm{~min} /$ week in total PA. The proportion of adolescents who met the PA recommendations ( $\geq 420 \mathrm{~min} /$ week) was $12.7 \%$ and was higher in boys and adolescents with higher socioeconomic status. Active transport contributed more to total PA in girls than in boys (29\% vs $18 \%$ ). Leisure PA and physical education classes were higher in boys and adolescents with high socioeconomic status. Boys with higher socioeconomic status and maternal education had higher levels of total PA.

Children and adolescents aged 5-17 years are advised to accumulate at least $60 \mathrm{~min}$ of daily MVPA ( $\geq 420 \mathrm{~min} /$

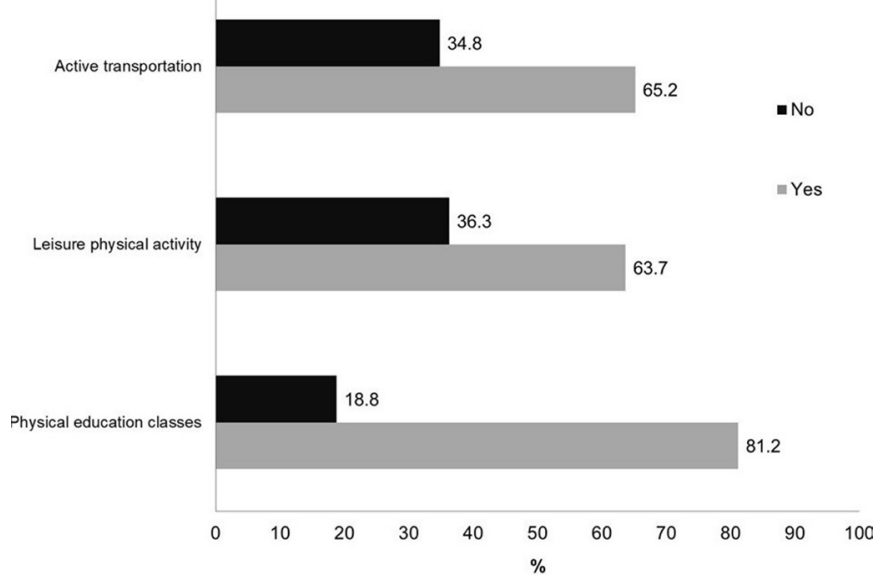

Figure 2 Proportion (\%) of adolescents practising physical activity at least 2 days per week by domain of physical activity. SP-PROSO, 2017. week). ${ }^{3}$ Compared with high-income countries, we found a higher prevalence of insufficient PA in adolescents in Sao Paulo $(87.3 \%)$ than in adolescents in Australia $(83.5 \%)$, USA $(70.9 \%)$, Denmark $(80.4 \%)$ and Spain $(74.4 \%)$. Worldwide, $81 \%$ of adolescents aged 11-17 years do not achieve this goal. ${ }^{4}$ In other Brazilian cities, the proportion of adolescents that do not meet the PA guidelines is lower than in Sao Paulo; eg, $60 \%$ in Distrito Federal, $63.2 \%$ in Rio de Janeiro and $64.1 \%$ in Rio Grande do Sul. ${ }^{29}$ These differences in PA across countries and cities are not well characterised. Heterogeneity across countries in terms of socioeconomic and environmental determinants of PA domains could certainly play a role. ${ }^{4}$ Intervention programmes should consider PA patterns to encourage PA practice among adolescents in the city of Sao Paulo.

Sao Paulo has been described as a city with a large disorganised urban sprawl. In the past 70 years, there has been an increase in violence and a decrease in public open spaces in peripheral regions and in low socioeconomic areas. These facts may explain the higher prevalence of physical inactivity among adolescents in Sao Paulo compared with other cities. However, in the last 10 years, different interventions have aimed to change this scenario. The New Master Plan to reduce environmental inequities was implemented in $2014 .^{20}$ Thereafter, programmes such as 'ruas de lazer' were implemented, where streets are closed to cars and open to the population on weekends. There was also an increase in bike paths and programmes such as 'ciclofaixas de lazer', where part of the streets and avenues are open to cyclists on weekends. Finally, green areas such as squares and parks around the city have also been expanded and valued as important public spaces for PA. ${ }^{21}$

In our study, patterns of domain-specific PA were different between boys and girls. Active transportation 


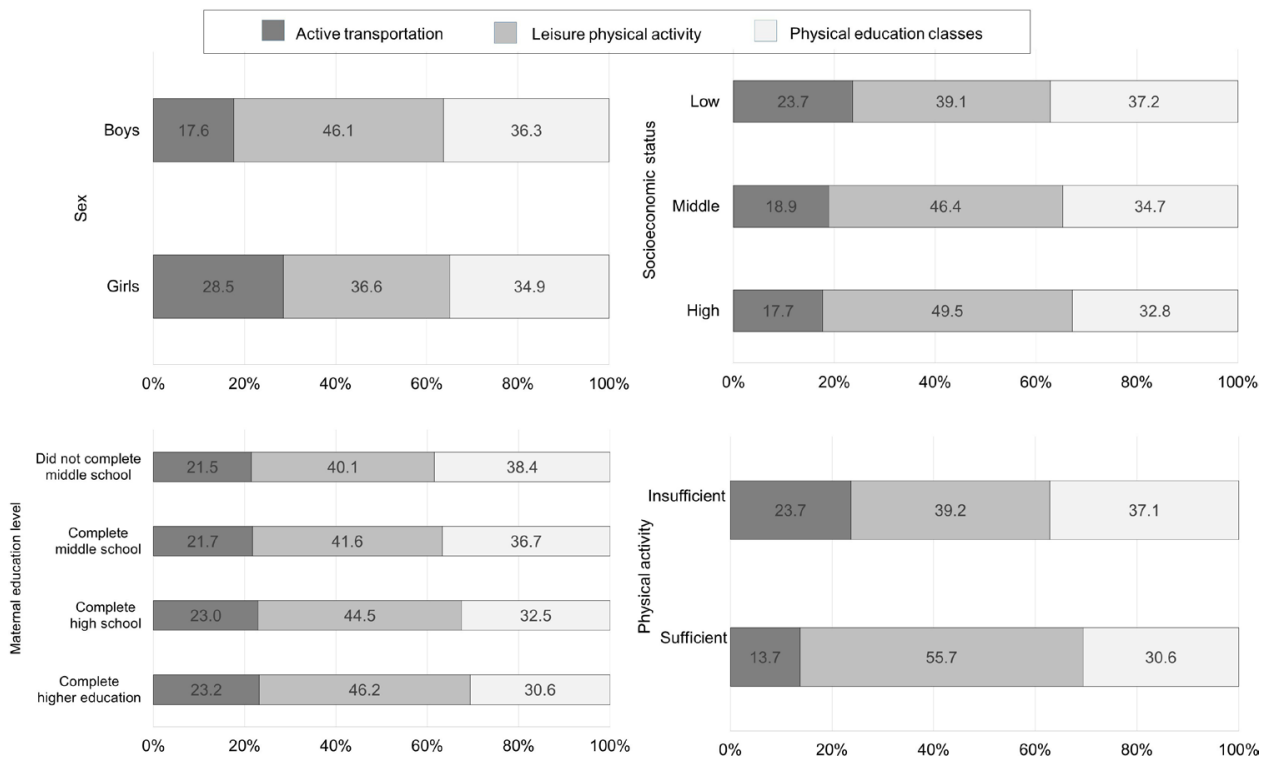

Figure 3 Proportion (\%) of domains of physical activity by sex, socioeconomic status, maternal education level and physical activity guidelines. SP-PROSO, 2017

was higher, in absolute and relative terms, in girls than in boys. In contrast, boys were more active than girls in the domains of leisure and physical education classes. These findings are similar to previous studies conducted worldwide. ${ }^{40}$ In addition, the contribution of leisure PA and physical education classes to total PA was found to be $46.1 \%$ and $36.3 \%$ in boys and $36.6 \%$ and $34.9 \%$ in girls, respectively. Boys tend to participate more frequently in high-intensity PA (eg, soccer, basketball, volleyball), whereas girls tend to engage in light to moderate-intensity activities, such as walking and water activities.$^{31}$ In addition, boys report greater social support from parents and friends, have fewer barriers to getting involved in and a greater perception of self-efficacy for PA. In contrast, girls show more negative attitudes towards PA, refer to more barriers and perceive less favourable environments for $\mathrm{PA} .^{32} \mathrm{PA}$ interventions, especially in leisure time, are important to increase the total PA of adolescent girls in Sao Paulo. For this reason, it is imperative to identify girls' preferences, reasons and barriers to participate in these activities.

Adolescents with a high socioeconomic status showed a higher PA level than the lower socioeconomic groups. Higher socioeconomic status has been associated with more opportunities at school and in the community for PA. ${ }^{7}$ Similarly, our results showed that adolescents with a higher maternal education level tend to have higher levels of total PA, especially in the leisure PA domain, possibly reflecting a higher socioeconomic status. Several methods have been used to determine the socioeconomic status (eg, family income, professional occupation, parental education and place of residence), which have been shown to influence adolescent PA in particular ways. ${ }^{7}$ For example, while the poorest groups walk more to and from school or work and develop more household activities, wealthiest groups engage more frequently in leisure
PA, which could be explained by differences in access to financial and material resources. Different mechanisms may explain the relationship between parental education and PA. ${ }^{7}$ First, participation in many types of PA has financial costs (eg, purchasing equipment, monthly fees and transportation) that may not be affordable by the poorest families. ${ }^{33}$ Families with higher socioeconomic status usually live in neighbourhoods with better infrastructure for PA (eg, parks, squares, running/walking tracks or cycle paths). In addition, adults with higher education levels have higher PA levels, particularly during leisure time, ${ }^{34} 35$ which may positively influence adolescents' PA. ${ }^{13}$ Another plausible explanation for this association is that physically active parents are more likely to provide greater social support for adolescent PA. ${ }^{36}$

In our study, adolescents spent relatively little time on leisure PA and active transportation. Participants did, on average, $93 \mathrm{~min} /$ week of leisure PA and $44 \mathrm{~min} /$ week of active transportation. These domains accounted for only $23 \%$ and $41 \%$ of total PA, respectively. Active transportation to school is an important source of PA and has been associated with higher PA levels in adolescents. ${ }^{37-39}$ As only $65 \%$ of the participants engage in active transportation, school-based interventions aiming to promote walking or cycling to and from school are needed. Prevalences of active transportation in Latin American countries have been associated with different socioenvironmental characteristics. ${ }^{40}$ Safety, social support for commuting and the built environment have been reported to be important determinants of active transportation in adolescents. ${ }^{41}$

Physical education classes are a fundamental opportunity to promote PA. ${ }^{10}{ }^{42}$ Physical education classes may contribute considerably to adolescent PA, both directly, by offering PA in the class, and indirectly, by stimulating PA practice, favouring access to knowledge 


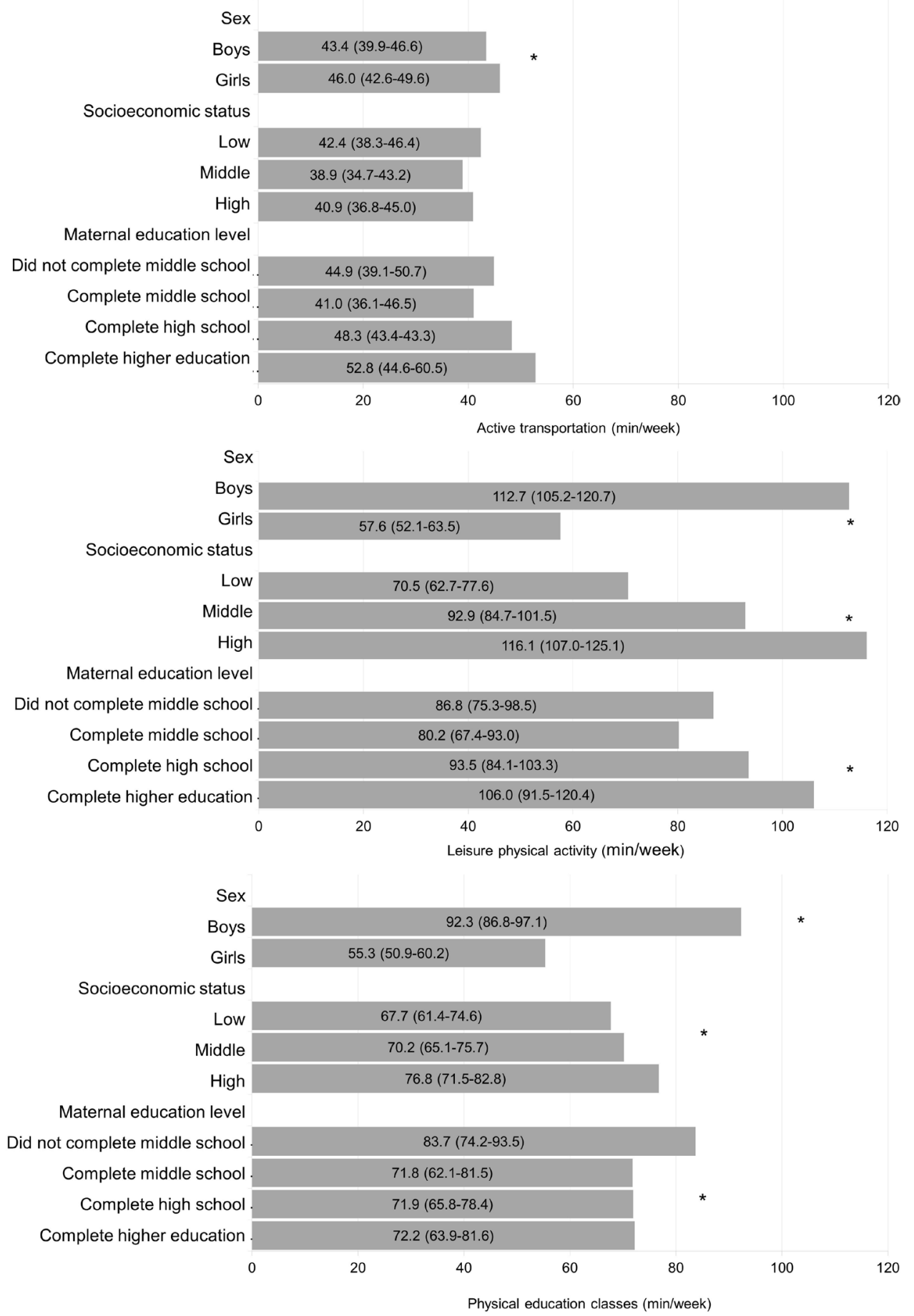

Figure 4 Domains of physical activity in minutes/week (mean and $95 \% \mathrm{Cl}$ ) by sex, socioeconomic status and maternal education level. ${ }^{*} P<0.05$.

and positive experiences with PA. ${ }^{42} \mathrm{~A}$ systematic review that estimated PA levels during physical education classes showed that, on average, youth spend $37 \%$ of their physical education time in MVPA. ${ }^{43}$ In another study, physical education classes contributed $30 \%$ to total PA. ${ }^{38}$ Adolescents who participate in physical education classes are more likely to be physically active ${ }^{42}{ }^{44}$ Physical education classes showed to be an important opportunity for adolescents' PA, especially for those with lower socioeconomic status and lower maternal education level. Policies aimed to promote PA should ensure, among other things, that frequency and quality physical education classes contribute to adolescents develop standards of behaviours that keep them physically active throughout their lives. ${ }^{45}$

Patterns of total and domain-specific PA may be useful for decision makers to plan and promote PA interventions. Decisions can be made to construct appropriate PA leisure environments, such as outdoor park courts, ${ }^{46}$ and improve the walkability of streets ${ }^{26}$ 
and cycle paths. Our results indicate that adolescents participating in leisure PA are more likely to achieve PA guidelines. In this sense, schools and decision makers should prioritise PA programmes focused on leisure activities to increase total PA in adolescents in Sao Paulo.

Our study has some limitations. Of the 61 private schools drawn, 26 refused and 3 did not respond, so they were excluded. Of the public schools, one state school and seven municipal schools were lost. Out-of-school adolescents were not included in our study. PA information was collected through a self-report questionnaire, and therefore measurement error probably occurred. Although participants were asked about the frequency and duration of each PA domain in a typical week, the questionnaire did not include information on the intensity of activities. ${ }^{47}$ However, this PA questionnaire has shown high relative accuracy. ${ }^{26}$ The maternal education variable had substantial missing data $(30 \%)$. However, missing data were not related to sex and socioeconomic status. Adolescents with missing maternal education data showed similar active transportation and participation in physical education classes. However, they tended to present higher levels of leisure PA (mean: $179.2 \mathrm{~min} /$ week; $P<0.001$ ) and total PA (mean: $75.2 \mathrm{~min} /$ week; $P<0.001$ ) compared with those who did answered a questionnaire about maternal education level (data not shown).

\section{CONCLUSIONS}

In this study, we found different patterns of total and domain-specific PA by sex, socioeconomic status and maternal education level in adolescents from Sao Paulo. Subgroups of adolescents with higher PA levels (boys and adolescents with high socioeconomic status and high maternal education level) tended to have more engagement in leisure PA. Routine PA transportation should also be highly encouraged to increase PA in adolescents. Future studies should seek to better understand the challenges of implementing and promoting PA by considering total and domain-specific PA patterns.

\section{Author affiliations}

${ }^{1}$ Facultad de Ciencias Médicas, Laboratorio de Ciencias de la Actividad Física, el Deporte y la Salud, Universidad de Santiago de Chile, Santiago de Chile, Chile 'Universidade Federal de São Paulo, Escola Paulista de Medicina, Departamento de Medicina Preventiva, São Paulo, SP, Brazil

${ }^{3}$ School of Arts, Sciences and Humanities, University of Sao Paulo, Sao Paulo, Brazil ${ }^{4}$ Graduate Program in Nutrition in Public Health, Department of Nutrition, School ofPublic Health, University of Sao Paulo, São Paulo, SP, Brazil

${ }^{5}$ Departamento de Medicina Preventiva, Faculdade de Medicina FMUSP, Universidade de Sao Paulo, Sao Paulo, SP, Brazil

\section{Twitter Maria Fernanda Tourinho Peres @none}

Acknowledgements The authors would like to thank the adolescents participating of the SP-PROSO.

Contributors GF and LFMdR had full access to all study data and were responsible for the integrity of the data and the accuracy of the data analysis. The corresponding author had final responsibility for the decision to submit for publication. MFP was the PI responsible for study concept, design and data collection. GF and LFMdR prepared the first draft. GF, LFMdR, GW, AF and MFP drafted and critically revised the manuscript for important intellectual content and gave final approval of the version to be published.

Funding The present research received financial support from the British Academy/Newton Foundation grant \#AF160099), Sao Paulo Research Foundation (FAPESP) grant \#2016/22259-4.

Competing interests None declared.

Patient and public involvement Patients and/or the public were not involved in the design, or conduct, or reporting, or dissemination plans of this research.

Patient consent for publication Not required.

Ethics approval The protocol was approved by the Ethics and Research Committee of the University of Sao Paulo, School of Medicine (Comitê de Ética e Pesquisa da Faculdade de Medicina da Universidade de São Paulo, records no. 1.719.856) and the National Commission for Research Ethics (Comissão Nacional de Ética em Pesquisa (CONEP), records no. 2.014.816).

Provenance and peer review Not commissioned; externally peer reviewed.

Data availability statement Data are available upon reasonable request. All data relevant to the study are included in the article or uploaded as supplementary information. All data relevant to the study are included in the article or uploaded as supplementary information.Data are available upon reasonable request from the corresponding author.

Open access This is an open access article distributed in accordance with the Creative Commons Attribution Non Commercial (CC BY-NC 4.0) license, which permits others to distribute, remix, adapt, build upon this work non-commercially, and license their derivative works on different terms, provided the original work is properly cited, appropriate credit is given, any changes made indicated, and the use is non-commercial. See: http://creativecommons.org/licenses/by-nc/4.0/.

ORCID iD

Gerson Ferrari http://orcid.org/0000-0003-3177-6576

\section{REFERENCES}

12018 Physical Activity Guidelines Advisory Committee. 2018 physical activity guidelines advisory committee scientific report. Washington, DC: US Department of Health and Human Services, 2018.

2 Rezende LFMde, Lee DH, Keum N, et al. Physical activity during adolescence and risk of colorectal adenoma later in life: results from the nurses' health study II. Br J Cancer 2019;121:86-94.

3 World Health Organization. Global recommendations on physical activity for health. Geneva: WHO, 2010.

4 Guthold R, Stevens GA, Riley LM, et al. Global trends in insufficient physical activity among adolescents: a pooled analysis of 298 population-based surveys with 1.6 million participants. Lancet Child Adolesc Health 2020;4:23-35.

$5 \mathrm{Kemp} \mathrm{BJ}$, Cliff DP, Chong KH, et al. Longitudinal changes in domains of physical activity during childhood and adolescence: a systematic review. J Sci Med Sport 2019;22:695-701.

6 Bauman AE, Reis RS, Sallis JF, et al. Correlates of physical activity: why are some people physically active and others not? Lancet 2012;380:258-71.

7 Stalsberg R, Pedersen AV. Effects of socioeconomic status on the physical activity in adolescents: a systematic review of the evidence. Scand J Med Sci Sports 2010;20:368-83.

8 Hallal PC, Knuth AG, Cruz DKA, et al. [Physical activity practice among Brazilian adolescents]. Cien Saude Colet 2010;15:3035-42.

9 Deforche B, Van Dyck D, Verloigne M, et al. Perceived social and physical environmental correlates of physical activity in older adolescents and the moderating effect of self-efficacy. Prev Med 2010;50:S24-9.

10 de Rezende LFM, Azeredo CM, Silva KS, et al. The role of school environment in physical activity among Brazilian adolescents. PLoS One 2015;10:e0131342.

11 Taylor JB, Wright AA, Dischiavi SL, et al. Activity demands during multi-directional team sports: a systematic review. Sports Med 2017;47:2533-51.

12 Demographia. Demographia world urban areas: 15th annual edition: 201904 Demographia. St. Louis, Missouri-Illinois Urban Area, USA, 2019.

13 Greene J, Guanais F. An examination of socioeconomic equity in health experiences in six Latin American and Caribbean countries. Rev Panam Salud Publica 2018;42:e127. 
14 Pesquisa nacional de saúde do escolar. 2015 / IBGE, Coordenação de População E Indicadores Sociais. Rio de Janeiro: IBGE, 2016: 132.

15 Vigitel Brasil 2018. vigilância de fatores de risco e proteção para doenças crônicas por inquérito telefônico : estimativas sobre frequência e distribuição sociodemográfica de fatores de risco e proteção para doenças crônicas nas capitais dos 26 estados brasileiros e no Distrito Federal em 2018 / Ministério da Saúde, Secretaria de Vigilância em Saúde, Departamento de Análise em Saúde e Vigilância de Doenças não Transmissíveis. Brasília: Ministério da Saúde, 2019: 132.

16 Van Hecke L, Loyen A, Verloigne $M$, et al. Variation in population levels of physical activity in European children and adolescents according to cross-European studies: a systematic literature review within DEDIPAC. Int J Behav Nutr Phys Act 2016;13:70.

17 Varela AR, Pratt M, Powell K, et al. Worldwide surveillance, policy, and research on physical activity and health: the global Observatory for physical activity. J Phys Act Health 2017;14:701-9.

18 Azeredo CM, de Rezende LFM, Mallinson PAC, et al. Progress and setbacks in socioeconomic inequalities in adolescent health-related behaviours in Brazil: results from three cross-sectional surveys 2009 2015. BMJ Open 2019;9:e025338.

19 Ferrari GLdeM, Kovalskys I, Fisberg M, et al. Anthropometry, dietary intake, physical activity and sitting time patterns in adolescents aged 15-17 years: an international comparison in eight Latin American countries. BMC Pediatr 2020;20:24.

20 Secretaria Municipal de Desenvolvimento Urbano. Plano Diretor Estratégico do Município de São Paulo. Available: https://www. prefeitura.sp.gov.br/cidade/secretarias/urbanismo/legislacao/plano_ diretor/index.php?p=201105 [Accessed 12 Apr 2020].

21 Hensley M, Mateo-Babiano D, Minnery J. Healthy places, active transport and path dependence: a review of the literature. Health Promot J Austr 2014;25:196-201.

22 Peres MFT. Violência, bullying E repercussões Na saúde: resultados do projeto São Paulo para O desenvolvimento social de crianças $E$ adolescentes (SP-PROSO). Departamento de medicina Preventiva/ FMUSP 2018:1-154

23 World Health Organization. Global school-based student health surveillance - GSHS. WHO, 2009.

24 Eaton DK, Kann L, Kinchen S, et al. Youth risk behavior surveillance -United States- 2009. 148. United States: Centers for Disease Control and Prevention (CDC), 2010.

25 Instituto Brasileiro de Geografia e Estatística. Pesquisa Nacional de Saúde Escolar. Rio de Janeiro: IBGE, 2013.

26 Tavares LF, Castro IRRde, Cardoso LO, et al. [Validity of indicators on physical activity and sedentary behavior from the Brazilian National School-Based Health Survey among adolescents in Rio de Janeiro, Brazil]. Cad Saude Publica 2014;30:1861-74.

27 Barros AJD, Victora CG. [A nationwide wealth score based on the 2000 Brazilian demographic census]. Rev Saude Publica 2005;39:523-9.

28 IBM Corporation. IBM SPSS statistics for windows, version 22.0. Armonk, NY: IBM Corporation, 2013.

29 Brazilian Institute of Geography and Statistics. Pesquisa Nacional de Saúde do Escolar (PeNSE), 2015. Available: https://biblioteca.ibge. gov.br/visualizacao/livros/liv97870.pdf [Accessed 7 Jan 2020].
30 Kidokoro T, Tanaka H, Naoi K, et al. Sex-specific associations of moderate and vigorous physical activity with physical fitness in adolescents. Eur J Sport Sci 2016;16:1159-66.

31 Vilhjalmsson R, Kristjansdottir G. Gender differences in physical activity in older children and adolescents: the central role of organized sport. Soc Sci Med 2003;56:363-74

32 Sallis JF, Prochaska JJ, Taylor WC. A review of correlates of physical activity of children and adolescents. Med Sci Sports Exerc 2000;32:963-75.

33 Smith M, Hosking J, Woodward A, et al. Systematic literature review of built environment effects on physical activity and active transport - an update and new findings on health equity. Int J Behav Nutr Phys Act 2017:14:158.

34 Farias Júnior JCde, Lopes AdaS, Mota J, et al. Physical activity practice and associated factors in adolescents in northeastern Brazil. Rev Saude Publica 2012;46:505-15.

35 López EB, Yamashita T. The relationship of education and acculturation with vigorous intensity leisure time physical activity by gender in Latinos. Ethn Health 2018;23:797-812.

36 Gill M, Chan-Golston AM, Rice LN, et al. Correlates of social support and its association with physical activity among young adolescents. Health Educ Behav 2018;45:207-16.

37 Sprengeler O, Wirsik N, Hebestreit A, et al. Domain-specific selfreported and objectively measured physical activity in children. Int $J$ Environ Res Public Health 2017;14:242.

38 Slingerland M, Borghouts LB, Hesselink MKC. Physical activity energy expenditure in Dutch adolescents: contribution of active transport to school, physical education, and leisure time activities. J Sch Health 2012;82:225-32.

39 Ferrari GLdeM, Matsudo V, Barreira TV, et al. Correlates of moderateto-vigorous physical activity in Brazilian children. J Phys Act Health 2016;13:1132-45.

41 Ferrari GLdeM, Kovalskys I, Fisberg M, et al. Socio-Demographic patterns of public, private and active travel in Latin America: cross-sectional findings from the ELANS study. $J$ Transp Health 2020;16:100788.

41 Giles-Corti B, Kelty SF, Zubrick SR, et al. Encouraging walking for transport and physical activity in children and adolescents: how important is the built environment? Sports Med 2009;39:995-1009.

42 Meyer U, Roth R, Zahner L, et al. Contribution of physical education to overall physical activity. Scand J Med Sci Sports 2013;23:600-6.

43 Fairclough SJ, Stratton G. A review of physical activity levels during elementary school physical education. J Teach Phys Educ 2006;25:240-58.

44 de Rezende LFM, Azeredo CM, Canella DS, et al. Sociodemographic and behavioral factors associated with physical activity in Brazilian adolescents. BMC Public Health 2014;14:485.

45 World Health Organization. Global action plan for the prevention and control of noncommunicable diseases 2013-2020. Geneva: WHO 2013. https://www.who.int/nmh/events/ncd action_plan/en/

46 Sallis JF, Cerin E, Conway TL, et al. Physical activity in relation to urban environments in 14 cities worldwide: a cross-sectional study. Lancet 2016:387:2207-17.

47 Colley RC, Butler G, Garriguet D, et al. Comparison of self-reported and accelerometer-measured physical activity in Canadian adults. Health Rep 2018;29:3-15. 